\title{
The effects of lidocaine and procaine on microRNA expression of adipocyte-derived adult stem cells
}

\author{
Sang Hoon Sung ${ }^{1}$ Jeong Gil Lee ${ }^{1}$, Soo Bong Yu ${ }^{1}$, Hee Kyung Chang ${ }^{2}$, and Sie Jeong Ryu ${ }^{1}$ \\ Departments of ${ }^{1}$ Anesthesiology and Pain Medicine, ${ }^{2}$ Pathology, Kosin University College of Medicine, Busan, Korea
}

Background: The microRNA (miRNA) pathway has emerged as one of the biologic pathways implicated in stem cell regulation. miRNA is a noncoding, single-stranded RNA consisting of 20-25 nucleotides that inhibits the protein production at the step of translation. The molecular effects of lidocaine and procaine on adipose stem cells were investigated by examining RNA expression array.

Methods: Adipose stem cells were isolated from a prior abdominal liposuction procedure. The human adipose stem cells were cultured and then added to a mixture of $1 \mathrm{ml}$ of culture medium plus $1 \mathrm{ml}$ of $2 \%$ lidocaine or $2 \%$ procaine for the duration of 30 minutes. The expression levels of miRNAs were estimated by using peptide nucleic acid (PNA)miRNA array analysis throughout the denaturation and hybridization processes after the isolation of miRNA. The miRNAs detected by microarray that either decreased by half fold or increased by 1.5 fold from the control level were interpreted as significant.

Results: According to microarray analysis there were 61 miRNAs in total, and no miRNA had decreased expression levels. The stem cells treatment with lidocaine showed 4 alteration of expression with miR-9a* (1.53 fold), miR-29a (1.64 fold), miR-296-5p (1.64 fold) and miR-373 (1.94 fold). The stem cells treated with procaine showed 32 miRNAs that were significantly up-regulated with a range of 1.5 to 2.06 fold. They were stem cell differentiation-related miRNAs, apoptosis and cell cycle-associated miRNAs, immunity-associated miRNAs and hormonal response-related miRNAs.

Conclusions: Lidocaine and procaine affect the miRNA expression on adipose stem cells and the effect of procaine is more marked than that of lidocaine. (Korean J Anesthesiol 2012; 62: 552-557)

Key Words: Lidocaine, MicroRNA, Procaine, Stem cells.

Received: February 1, 2012. Revised: February 20, 2012. Accepted: March 6, 2012.

Corresponding author: Sie Jeong Ryu, M.D., Department of Anesthesiology and Pain Medicine, Kosin University College of Medicine, 34, Anamdong, Seo-gu, Busan 602-702, Korea. Tel: 82-51-990-6265, Fax: 82-51-254-2504, E-mail: siejeong@ns.kosinmed.or.kr

() This is an open-access article distributed under the terms of the Creative Commons Attribution Non-Commercial License (http:// creativecommons.org/licenses/by-nc/3.0/), which permits unrestricted non-commercial use, distribution, and reproduction in any medium, provided the original work is properly cited. 


\section{Introduction}

In recent years, the clinical application of stem cells has emerged. In mammals, there are 2 broad types of stem cells: embryonic stem cells and adult stem cells. Mesenchymal stem cells have been isolated from several adult tissue sources, such as bone marrow, placenta, and adipose tissues [1-3]. Among these, adipose stem cell has been applied for autologous transplantation under local anesthesia. Stem cells are biological cells found in all multicellular organisms, which can divide (through mitosis), differentiate into diverse specialized cell types, and can self-renew to produce more stem cells. Stem cells suggest that a specific molecular control network underlies their unique features [1-3]. The microRNA (miRNA) pathway has emerged as one of the biologic pathways implicated in stem cell regulation [4].

The miRNA, a family of small non-coding RNA species with approximately 22 nucleotides, can cause either miRNA degradation or translational repression. Recent studies have provided evidence that miRNA affect critical pathways of cell proliferation and several biological processes that include cell differentiation, development, metabolism, tumorigenesis and other diseases by negative regulation of protein-coding genes $[4,5]$. Recently the study has been made in miRNA expression and as a biologic role in animal development, including the differentiation and maintenance of stem cells $[6,7]$. Investigation of the gene regulation mediated by miRNA has pointed to new directions for the therapeutic application of stem cells $[4,6,7]$.

Local anesthetics can adversely affect cell growth in vitro. Their effects on wound healing are controversial, however, the adverse effects of local anesthetics on wound healing at surgical sites have been suggested, and may be related to their cytotoxicity [8-10]. However, little has been reported about the relationship between miRNA and local anesthetics, especially on stem cells. Therefore, this study attempted to explore the molecular effects of local anesthetics on stem cells and to examine miRNA expression profiles.

\section{Materials and Methods}

\section{Human adipose-derived stem cells}

Adipose-derived stem cells (ASC) (provided by Dr. YI Yang) were isolated from lipoaspirates from patients undergoing cosmetic liposuction, as described by Zuk et al. [11]. In accordance with a consensus reached by the investigators, the author referred to this adherent cell population as ASC. Briefly, the tissue was digested for $45 \mathrm{~min}$ with $\mathbf{0 . 0 7 5 \%}$ collagenase I (Gibco, New York, USA). The stromal-vascular fraction was separated from the remaining fibrous material and the floating adipocytes by centrifugation at $300 \mathrm{X}$ g. The sedimented cells were filtered through a $100 \mu \mathrm{m}$ pore filter. Erythrocyte contamination was reduced by density gradient centrifugation with Bicoll (Biochrom, Munich, Germany). High contamination with erythrocytes was found to markedly decrease cell adherence and proliferation. A preceding density gradient separation provided a better yield of adherent cells than treatment with an erythrocyte lysing buffer. For initial cell culture and expansion of the cells, DMEM with a physiologic glucose concentration (100 mg/dl) supplemented with $10 \%$ fetal calf serum was used. Primary cell isolates and cultured cells were characterized as described by Brzoska et al. [12]. Cultured ASC were CD29+, $\mathrm{CD} 44+, \mathrm{CD} 49 \mathrm{a}+, \mathrm{CD} 73+, \mathrm{CD} 90+, \mathrm{CD} 105+, \mathrm{CD} 166+$, and CD14-, CD31-, CD45-. In vitro differentiation potential of ASC was proven by specific media and described. For these experiments, the 2 nd -5 th passage of ASC were used.

\section{Cell culture}

Cells were grown in T75 culture flasks containing DMEM-F12 supplemented with $10 \%$ fetal bovine serum (FBS), $1 \%$ antibiotics (10 U/L penicillin and $10 \mathrm{ug} / \mathrm{L}$ streptomycin), $10 \mathrm{ng} / \mathrm{ml}$ EGF and $2 \mathrm{ng} / \mathrm{ml}$ in a humidified $5 \% \mathrm{CO}_{2}$ atmosphere at $37^{\circ} \mathrm{C}$. Upon reaching confluence, cells were detached using TrypsinEDTA solution.

\section{Treatment with local anesthetics}

Human adipose stem cells were treated with $1 \mathrm{ml}$ of $2 \%$ lidocaine (Lidocaine $\mathrm{HCl}$, Huons, Korea) and 2\% procaine (Procaine $\mathrm{HCl}$, Daehan, Korea) admixed with $1 \mathrm{ml}$ culture media for 30 minutes, in each. Viability was determined directly after treatment and during the ensuing cultivation. A $1 \times 10^{6}\left(28 \times 10^{4}\right.$ cell $\left./ \mathrm{cm}^{2}\right)$ of cells was cultured in T75 culture flask containing DMEM-F12 at $37^{\circ} \mathrm{C}$ for 72 hours and then to a mixture of $1 \mathrm{ml}$ of culture medium plus $1 \mathrm{ml}$ of $2 \%$ lidocaine or $2 \%$ procaine for 30 minutes. This experiment was set up to approach the in vivo dilution, because a lack of nutrients may cause cell death, culture medium was added in this protocol. After 30 minutes of treatment, local anesthetics were removed and washed with $5 \mathrm{ml} \mathrm{FBS}$-free media, then cells were harvested and transferred into a $1.5 \mathrm{ml}$ tube and then the tube was frozen immediately to prevent RNA degradation.

\section{miRNA extraction}

The total RNA of each sample was extracted using the Trizol reagent (Life Technologies, Carlsbad, CA, USA) according to the instructions of the manufacturer. Low molecular weight (LMW) enriched RNA was isolated from 50 ug of total RNA 
using the mirVana miRNA extraction kit (Ambion, Inc, Austin, TX, USA), and quantified using a ND-1000 spectrophotometer (NanoDrop Technologies, Wilmington, DE, USA). RNA quality was evaluated using the Agilent 2100 Bioanalyzer (Agilent Technologies, Santa Clara, CA, USA).

\section{Microarray analysis}

Peptide nucleic acid (PNA)-miRNA array kit (Panazene, Daejeon, Korea) was used for miRNA expression profiling. The used PNA in PNA-miRNA array is an artificial nucleotide, in which the entire negatively charged sugar-phosphate backbone is replaced with a neutral $\mathrm{N}$-(2-amino ethyl)-glycine units repeatedly linked by peptide bonds. Because PNA is uncharged unlike DNA, the electrostatic repulsion is greatly reduced between PNA/RNA duplex compared to its DNA/RNA equivalent, which results in a stronger binding affinity.

\section{Denaturation}

An miRNA denaturation mixture containing miRNA 400 ng, RNase-free water 15 ug was prepared. The mixture was incubated at $95^{\circ} \mathrm{C}$ in a circulating water bath or heat block for 5 minutes and then immediately transferred to ice.

\section{Hybridization}

Eighty-five microliter of hybridization mixture was added to $15 \mathrm{ul}$ of denatured RNA sample to a total volume of $100 \mathrm{ul}$ and then was mixed well and gently vortexed for $2-3$ seconds. An incubator, a hybridization oven, was preheated to $55^{\circ} \mathrm{C}$ and was set up on a slide chamber on a microarray slide. All mixtures were added into each well. The mixture was hybridized at $55^{\circ} \mathrm{C}$ for 4 hours. Humidity was maintained to prevent desiccation.

\section{Washing the microarray slides}

The $20 \mathrm{X}$ washing buffer was diluted to a $1 \mathrm{X}$ washing buffer of $250 \mathrm{ml}$. A $1 \mathrm{X}$ washing buffer was added with a magnetic stir bar to a glass jar. The slide chamber was carefully removed from the microarray slides. The slides were loaded into a slide holder and immersed in $1 \mathrm{X}$ washing buffer in a glass jar. The slides were washed at room temperature for 5 minutes in $1 \mathrm{X}$ washing buffer. The buffer was decanted. This washing step was repeated with fresh washing buffer. The washed microarray slide was spun dry at 1,000 rpm for 5 minutes.

\section{Ligation reaction}

The $10 \mathrm{X}$ T4 RNA ligase buffer was warmed at $37^{\circ} \mathrm{C}$ and vortexed until all precipitates were dissolved. The ligation mixture containing 10 X T4 RNA ligase buffer 10 ul, $0.1 \%$ BSA 2 ul, pCp-Cy3 3 ul, T4 RNA ligase (10 U/ul) 1 ul, and RNase-free water $84 \mathrm{ul}$ were prepared. A slide chamber was set up on the hybridized microarray slide. Immediately $100 \mathrm{ul}$ of the ligation mixture was added into each well and then was incubated at $37^{\circ} \mathrm{C}$ for 2 hours in a humidified condition. Then, the ligation mixture was washed immediately.

\section{Scanning and image analysis}

Hybridized arrays were scanned using an Axon GenePix 4000B scanner (Molecular devices Corporation, Sunnyvale, CA, USA) and median spot intensities were collected using Axon GenePix 4.0 (Molecular Devices, Sunnyvale, CA, USA). Expression profiling analysis was performed using GeneSpring 7.0 (Agilent Technologies, Santa Clara, CA, USA). The expression level was altered significantly at more than 1.5 fold or at less than 0.5 fold. Array experiments were carried out in duplicate.

\section{miRNA target predictions}

The human targets of the differentially expressed miRNAs were predicted using public Web-based prediction tools, such as TargetScan, PicTar, and miRBase Targets. For references to the published studies, a list of chosen miRNAs were based on miRNAs showing at least a 1.5 fold up-regulation or a 0.5 fold down-regulation in the least selected putative targets as predicted using a combination of PicTar, TargetScan, and miRBase targets.

\section{Results}

The used RNA integrity number (RIN) value is a eukaryotic total RNA sample quality index that based on 1 to 10 ranged
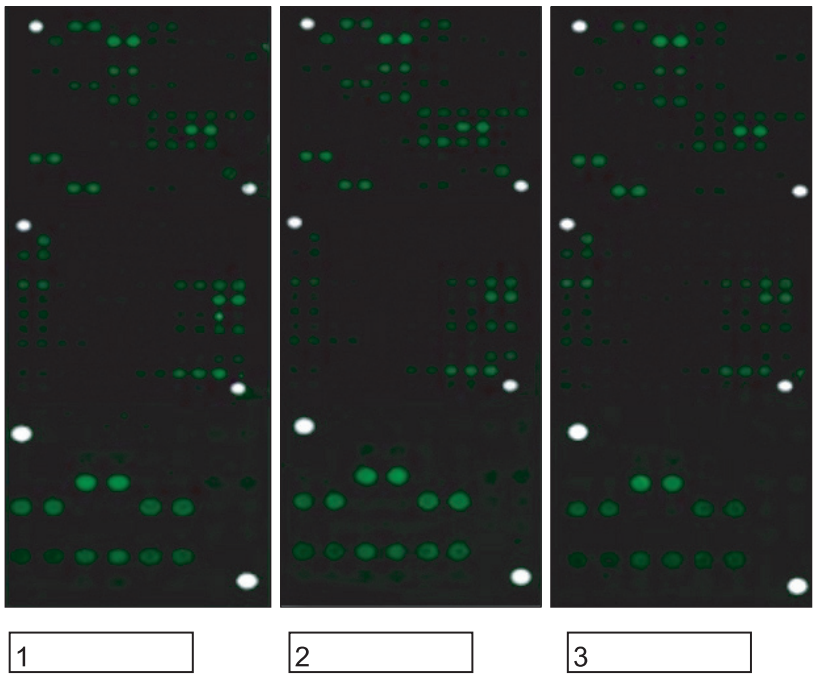

Fig. 1. The image of adipose stem cells microarray. Control (1), treated with lidocaine (2), and procaine (3). There were no miRNAs with decreased expression levels. 


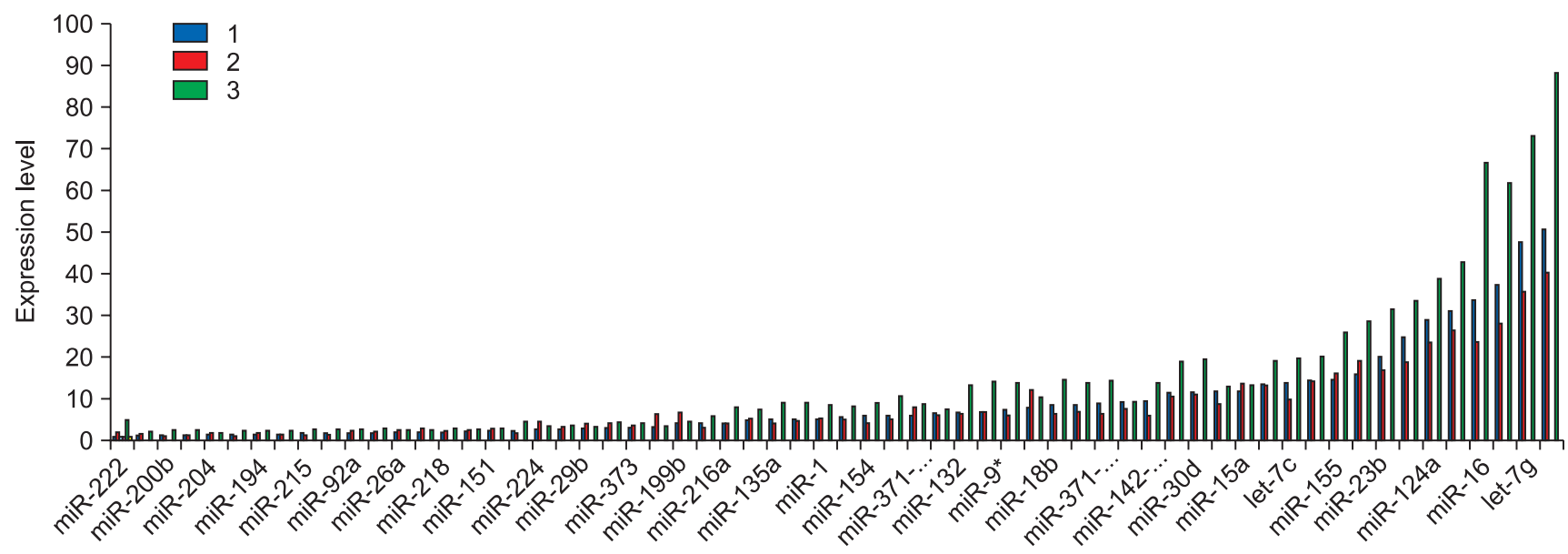

Fig. 2. The expression of miRNAs on adipose stem cells. There were 4 miRNAs in treatment with lidocaine (2, red color) and 32 miRNAs in treatment with procaine (3, green color) showing at least 1.5 fold differences compared with control (1, blue color).

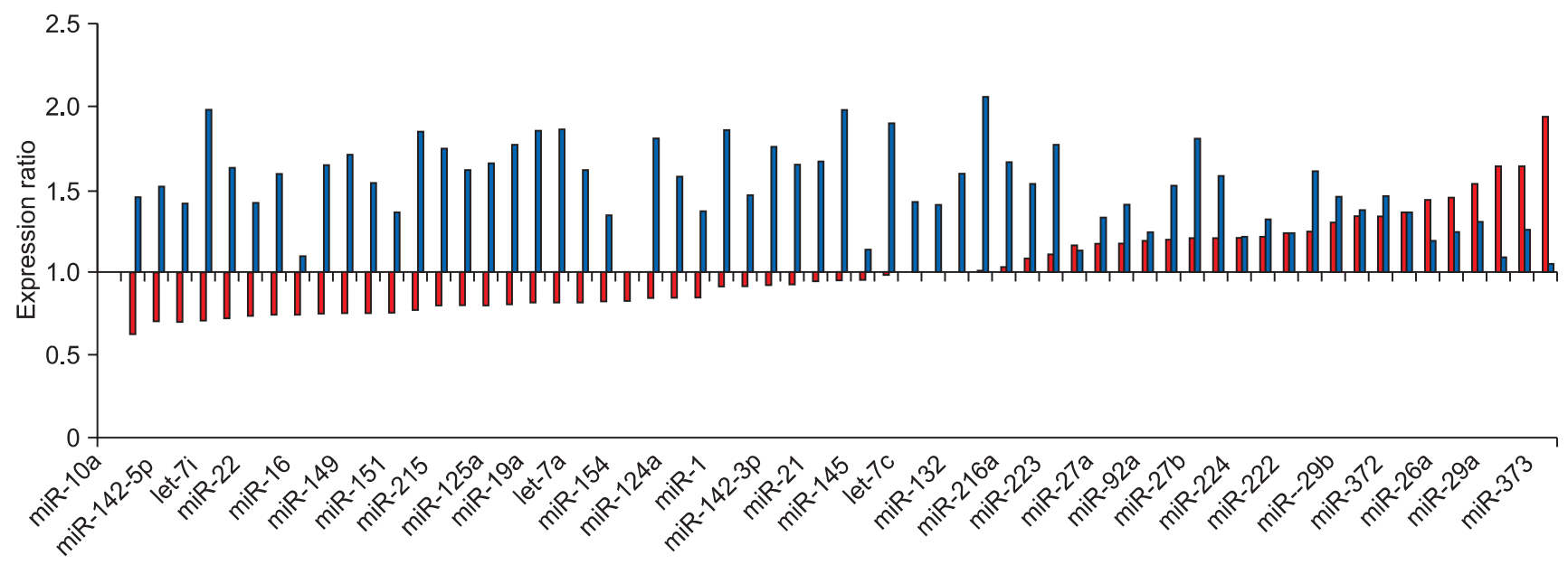

Fig. 3. The expression ratio of miRNAs on adipose stem cells. There are 4 miRNAs showing at least 1.5 fold differences in lidocaine treatment (red color), while 32 miRNAs are significantly up-regulated with range of 1.5 to 2.06 fold in procaine treatment (blue color).

statistical values of migration, peak pattern, and 28s/18s. The ratio of RNA quality for control and treated cells, ribosomal RNA ratio 28s $/ 18 \mathrm{~s}>1, \mathrm{OD}_{260} / \mathrm{OD}_{230}>2.0, \mathrm{OD}_{260} / \mathrm{OD}_{280}>1.8>1$, and RIN value was 6.5-7.0.

Among 61 miRNAs, let-7g, miR-16, miR-124a, miR-149, and miR-188-5p showed high expression with more than 30 .

According to the microarray analysis with 61 miRNAs in lidocaine treatment, there was no miRNA with decreased expression levels (Fig. 1 and 2). The stem cells with treatment of lidocaine showed alteration expression in 4 miRNAs including miR-9a* (1.53 fold), miR-29a (1.64 fold), miR-296-5p (1.64 fold) and miR-373 (1.94 fold) (Fig. 3).

With miRNA expression in procaine treatment, there were no miRNA significantly down-regulated, while 32 miRNAs were significantly up-regulated with range of 1.5 to 2.06 fold (Fig. 3). let-7b, -7i, -135b, -142-3p, -143, -149, -16, -186, -18b, -194, -204,
$-215,-216 a,-22,-222,-27 b, 92 a$ of miRNA expression shows 1.51.7 fold, and let-7g, -10b, -125a, -127-5p, -135a, -145, -148a, -151, $-154,-155,-188-5 p,-19 a,-200 b,-21$ of miRNA expression shows $1.71-2.00$ fold. The expression of miR-132 was 2.06 fold, which was the highest increase among 32 miRNAs.

\section{Discussion}

This study was aimed to investigate the molecular effect of lidocaine and procaine on adipose stem cells by miRNA expression array. Lidocaine and procaine presented different alteration patterns of miRNA expression. Few studies have identified miRNA expression patterns in adipose stem cells associated with local anesthetics.

The lidocaine treatment on adipose stem cells showed only 4 miRNA changes in expression profile, miR-9*, 29a, 296-5p and 
373, of which were associated with stem cell function including lipoapoptosis $[13,14]$. This means that the clinically available concentration with 30 minutes of treatment provide a little molecular effects associated with miRNA. This result is different from the previous report molecularly that is devastating results on chondrocytes after lidocaine treatment. Exposing the chondrocytes to a 50/50 mixture of culture medium and local anesthetics substantially decreased cytotoxicity but still showed high toxicity when compared with the saline group (90\% dead cells for lidocaine $2 \%, \mathrm{P}=0.047$ ) [15]. In this study, the hightoxicity was not presented, considering a 50/50 mixture of culture medium and $2 \%$ lidocaine was used. There is a report that low concentrations of lidocaine as would be seen in plasma after spinal, epidural, or plexus anesthesia did not significantly affect multiplication of fibroblasts and higher concentrations, as would be seen after tissue infiltration, severely inhibit fibroblast multiplication and thus may impair wound healing [10]. In this study, the expression of multiplication-associated miRNAs was not significantly changed. Local anesthetics used in this study contained sodium chloride as preservative, which would affect the results presented and there has been no published result to date about the relationship between miRNA and lidocaine, further future study is needed for verification of this result.

Otherwise, the procaine showed significant upregulation of 32 miRNAs expression. Among these, stem cell differentiationrelated miRNAs were let-7s, miR-10b, 19a, 27b, 125a, 135b, 145,155 , and 200b. let-7s showed $1.52-1.75$ fold, which are negative regulators of stem cell differentiation and essential for maintenance of an early developmental lineage [16]. Besides, let-7d regulates cocaine-induced plasticity [17]. The miRNA$200 \mathrm{~b}$ expression negatively regulates epithelial to mesenchymal transition that facilitates tissue remodeling during embryonic development and is viewed as an essential early step in tumor metastasis by targeting ZEB1 and SIP1 [18]. miR-373 significantly up-regulates tumor migration and invasion as metastasispromoting miRNAs [19].

A usual prediction with any one of the algorithms (PicTar, TargetScan, miRBase Targets) will yield hundreds of predicted targets for each miRNA. A list of selected target genes, which are of particular interest or significance in this study, for the differentially expressed miRNAs from adipose stem cell before and after treatment of anesthetics, are presented in Table 2. Most putative targets predicted in this study are homeo-box genes (HOX family), transcription factors (PPAR, RGS7BP, NR3C2, DFF45, EF2, ESR1, UBE2), growth, and apoptotic genes (RAS, BCL2, APC, p53, PTEN).

The various kinds of differentiation-associated miRNA were up-regulated. They are osteogenic differentiation (miR-135b) [20], monocytic differentiation (miR-155, 222) [21], miRNAs (miR-16, 133a, 145, 149, 186, 204) which cause apoptosis by targeting BCL2 [22], the DNA fragmentation factor-45 (DFF45) [23], and P2X7 [24]. Immunity-related miRNAs were miR-132, -142-3p, -155, -222. miR-155 is a critical regulator of immune cell development [25] and miR-132 potentiates cholinergic anti-inflammatory signaling [26]. Hormonalrelated miRNAs were miR-22, 125a, 135a. The miRNA, miR$135 \mathrm{a}$, can participate in the regulation of renin-angiotensinaldosterone system involved in blood pressure regulation by repression of the mineralocorticoid receptor gene NR3C2 [27]. The up-regulation of miR-194, whose potential role in this study cannot be assumed, was reported as an hepatocyte marker [28]. miR-143 (1.66 fold) and -200b (1.86 fold) was expressed highly, which have functioned in accelerating the rate of fat cell formation in preadipocytes [29]. The miRNA, miR-143, is involved in adipocyte differentiation and may act through the target gene ERK5, normally promotes adipocyte differentiation. Interestingly, miR-27b (1.58) which has the function of antiadipogenesis and muscle differentiation was also expressed simultaneously [30].

Although the miRNA expression is cell or tissue specific and is multifunctional with multitargets [5-7], therefore, the alteration of miRNA expression herein can speculate the cytotoxicity of local anesthetics on adipose stem cells.

In conclusion, these results suggests that local anesthetics affect miRNA expression on adipose stem cells and the effect of procaine is more marked than that of lidocaine, considering alteration of miRNAs' expression. Procaine can downregulate stem cell differentiation, immunity, and apoptosis up-regulation by expressing miRNAs on stem cells. Especially miRNA-132 might have an important role in procaine activity. As lidocaine has been frequently used in local anesthesia and miRNA affect critical pathway of several biological processes, further study will be needed about the effect of lidocaine on stem cells including function of miR-9*, 29a, 296-5p and 373.

\section{References}

1. Locke M, Feisst V, Dunbar PR. Concise review: human adiposederived stem cells: separating promise from clinical need. Stem Cells 2011; 29: 404-11.

2. Utsunomiya T, Shimada M, Imura S, Morine Y, Ikemoto T, Mori $\mathrm{H}$, et al. Human adipose-derived stem cells: potential clinical applications in surgery. Surg Today 2011; 41: 18-23.

3. Tremolada C, Palmieri G, Ricordi C. Adipocyte transplantation and stem cells: plastic surgery meets regenerative medicine. Cell Transplant 2010; 19: 1217-23.

4. Yi R, Fuchs E. MicroRNAs and their roles in mammalian stem cells. J Cell Sci 2011; 124: 1775-83.

5. Janga SC, Vallabhaneni S. MicroRNAs as post-transcriptional machines and their interplay with cellular networks. Adv Exp Med Biol 2011; 722: 59-74. 
6. Bartel DP. MicroRNAs: genomics, biogenesis, mechanism, and function. Cell 2004; 116: 281-97.

7. Bartel DP. MicroRNAs: target recognition and regulatory functions. Cell 2009; 136: 215-33.

8. Keck M, Zeyda M, Gollinger K, Burjak S, Kamolz LP, Frey M, et al. Local anesthetics have a major impact on viability of preadipocytes and their differentiation into adipocytes. Plast Reconstr Surg 2010; 126: $1500-5$.

9. Wolfe JW, Butterworth JF. Local anesthetic systemic toxicity: update on mechanisms and treatment. Curr Opin Anaesthesiol 2011; 24: 561-6.

10. Desai SP, Kojima K, Vacanti CA, Kodama S. Lidocaine inhibits NIH-3T3 cell multiplication by increasing the expression of cyclindependent kinase inhibitor 1A (p21). Anesth Analg 2008; 107: 15927.

11. Zuk PA, Zhu M, Mizuno H, Huang J, Futrell JW, Katz AJ, et al. Multilineage cells from human adipose tissue: implications for cellbased therapies. Tissue Eng 2001; 7: 211-28.

12. Brzoska M, Geiger H, Gauer S, Baer P. Epithelial differentiation of human adipose tissue-derived adult stem cells. Biochem Biophys Res Commun 2005 330: 142-50.

13. Han YC, Park CY, Bhagat G, Zhang J, Wang Y, Fan JB, et al. microRNA29a induces aberrant self-renewal capacity in hematopoietic progenitors biased myeloid development, and acute myeloid leukemia. J Exp Med 2010; 207: 475-89.

14. Zhou AD, Diao LT, Xu H, Xiao ZD, Li JH, Zhou H, et al. $\beta$-Catenin/ LEF1 transactivates the microRNA-371-373 cluster that modulates the Wnt/ $\beta$-catenin-signaling pathway. Oncogene 2011 [Epub ahead of print]

15. Jacobs TF, Vansintjan PS, Roels N, Herregods SS, Verbruggen G, Herregods LL, et al. The effect of lidocaine on the viability of cultivated mature human cartilage cells: an in vitro study. Knee Surg Sports Traumatol Arthrosc 2011; 19: 1206-13.

16. Yi R, Fuchs E. MicroRNAs and their roles in mammalian stem cells. J Cell Sci 2011; 124: 1775-83.

17. Chandrasekar V, Dreyer JL. microRNAs miR-124, let-7d and miR181a regulate cocaine-induced plasticity. Mol Cell Neurosci 2009; 42: 350-62.

18. Gregory PA, Bert AG, Paterson EL, Barry SC, Tsykin A, Farshid G, et al. The miR-200 family and miR-205 regulate epithelial to mesenchymal transition by targeting ZEB1 and SIP1. Nat Cell Biol 2008; 10: 593-601.
19. Huang Q, Gumireddy K, Schrier M, le Sage C, Nagel R, Nair S, et al. The microRNAs miR-373 and miR-520c promote tumour invasion and metastasis. Nat Cell Biol 2008; 10: 202-10.

20. Schaap-Oziemlak AM, Raymakers RA, Bergevoet SM, Gilissen C, Jansen BJ, Adema GJ, et al. MicroRNA hsa-miR 135b regulates mineralization in osteogenic differentiation of human unrestricted somatic stem cells. Stem Cells Dev 2010; 19: 877-85.

21. Forrest AR, Kanamori-Katayama M, Tomaru Y, Lassmann T, Ninomiya N, Takahashi Y, et al. Induction of microRNAs, mir-155, mir-222, mir-424 and mir-503, promotes monocytic differentiation through combinatorial regulation. Leukemia 2010; 24: 460-6.

22. Cimmino A, Calin GA, Fabbri M, Iorio MV, Ferracin M, Shimizu M, et al. miR-15 and miR-16 induce apoptosis by targeting BCL2. Proc Natl Acad Sci U S A 2005; 102: 13944-9.

23. Zhang J, Guo H, Qian G, Ge S, Ji H, Hu X, et al. MiR-145, a new regulator of the DNA fragmentation factor-45 (DFF45)-mediated apoptotic network. Mol Cancer 2011; 9: 211-3.

24. Zhou L, Qi X, Potashkin JA, Abdul-Karim FW, Gorodeski GI. MicroRNAs miR-186 and miR-150 down-regulate expression of the pro-apoptotic purinergic P2X7 receptor by activation of instability sites at the 3 '-untranslated region of the gene that decrease steady-state levels of the transcript. J Biol Chem 2008; 283: 28274-86.

25. O'Connell RM, Chaudhuri AA, Rao DS, Baltimore D. Inositol phosphatase SHIP1 is a primary target of miR-155. Proc Natl Acad Sci U S A 2009; 106: 7113-8.

26. Shaked I, Meerson A, Wolf Y, Avni R, Greenberg D, Gilboa-Geffen A, et al. MicroRNA-132 potentiates cholinergic anti-inflammatory signaling by targeting acetylcholinesterase. Immunity 2009; 31: 965 73.

27. Sõber S, Laan M, Annilo T. MicroRNAs miR-124 and miR-135a are potential regulators of the mineralocorticoid receptor gene (NR3C2) expression. Biochem Biophys Res Commun 2010; 391: 727-32.

28. Meng Z, Fu X, Chen X, Zeng S, Tian Y, Jove R, et al. miR-194 is a marker of hepatic epithelial cells and suppresses metastasis of liver cancer cells in mice. Hepatology 2010; 52: 2148-57.

29. Xie H, LimB, Lodish HF. MicroRNAs induced during adipogenesis that accelerate fat cell development are downregulated in obesity. Diabetes 2009; 58: 1050-7.

30. Karbiener M, Fischer C, Nowitsch S, Opriessnig P, Papak C, Ailhaud $\mathrm{G}$, et al. microRNA miR-27b impairs human adipocyte differentiation and targets PPARgamma. Biochem Biophys Res Commun 2009; 390: 247-51 